\title{
Diálogo entre autores: Berkeley e Bergson
}

\author{
Maria Adriana Camargo Cappello
}

Professora da Universidade Federal do Paraná (UFPR) 


\section{Diálogo entre autores: Berkeley e Bergson}

Neste artigo, proponho interpretar a redução berkelianista das coisas às ideias levando em conta uma aproximação entre a crítica à dupla existência dos objetos, subjacente a essa redução, e a crítica às teorias clássicas da representação, desenvolvida por Bergson no âmbito de sua teoria da percepção.

Palavras-chave: matéria, ideia, mente, representação, consciência

\section{Dialog between authors: Berkeley and Bergson}

In this article, I offer an interpretation of the Berkeley's reduction of things into ideas that takes into account an approximation between the criticism of the double existence of objects, implied in such reduction, andthe criticism of the classic theories of representation developed by Bergson in his theory of perception.

Key words: matter, idea, mind, representation, consciousness 


\section{Campo de imagens / ideias-coisas ${ }^{1}$}

O diálogo que aqui se propõe é aquele que, acreditamos, poderia se estabelecer entre as concepções de percepção desenvolvidas por Berkeley e por Bergson no âmbito das críticas, de cada um desses autores, à hipótese da dupla existência dos objetos. Esse diálogo tem como pano de fundo, de um lado, a crítica de Bergson às teorias clássicas da representação, cujos pressupostos, segundo o autor, mantinham-se subjacentes às mais variadas teorias vigentes em sua época sobre as relações entre a realidade psíquica e a matéria; de outro lado, a indistinção entre a concepção de matéria e de percepção da matéria proposta por Berkeley no contexto mesmo da enunciação das teorias clássicas da representação.

A questão que alimenta o diálogo é saber se a tese de Bergson segundo a qual, na percepção, entramos em contato com os objetos em sua própria natureza seguiria o mesmo caminho de superação das teorias da representação apontado por Berkeley. Essa hipótese nos põe, logo de início, diante de uma dificuldade: apesar de Bergson ter dado, em "A intuição filosófica", uma interpretação da redução berkelianista das coisas às ideias, que pode ser considerada favorável à hipótese que aqui nos propomos a investigar ${ }^{2}$, Bergson considerava

1 As considerações a respeito da filosofia de Berkeley e esta comparação entre essa filosofia e a de Bergson, no âmbito da crítica à teoria da representação, tomam como base a interpretação de Bento Prado Jr. sobre o tema, especificamente sua afirmação de que o campo de imagens proposto por Bergson seria correlato às ideias-coisas de Berkeley. Cf. Prado Jr. 5.

2 "L’intuition philosophique". In: Bergson 2, p. 127.: "Ce que l'idealisme de Berkeley signifie, c’est que la matière est coextensive à notre représentation, qu’elle n’as pas d’interieur, pas de dessous, qu'elle ne cache rien, ne renferme rien, qu'elle ne possède ni puissance 
que Berkeley, enquanto idealista, era um dos adeptos da teoria da representação a ser criticada. O interesse do diálogo talvez se encontre, então, não tanto em definir a interpretação de um dos autores na letra do texto do outro. Em vez disso, ao realçar a semelhança da crítica encontrada em um e outro, vale realçar também o aspecto crítico da filosofia de Berkeley, o que poderia nos levar a abandonar a cômoda posição de encarar o seu pensamento como mais um dogmatismo do qual acreditamos poder nos desfazer com bastante facilidade.

Para desenvolver tal hipótese interpretativa é preciso, em primeiro lugar, distinguir a filosofia de Berkeley do idealismo ao qual o próprio Bergson o filia e pelo qual o critica. Trata-se de um idealismo que se inscreveria entre aquelas filosofias decorrentes do dualismo de tipo cartesiano e que procuraria resolver o problema da representação, que tem suas raízes nesse dualismo, pela supressão de um dos termos em que ele se dá. É uma filosofia que, ao rejeitar o caminho da pura abstração e não tendo encontrado um critério empírico de adequação da representação em relação ao objeto representado, excluiria o objeto e ficaria apenas com a representação, batizando-a de "coisa". Esquecendo-se, portanto, de que esta não passaria de uma aparência e, pior, de que não pode haver aparência sem algo de que haja aparência.

Explicitemos, então, a crítica de Bergson ao pensamento que ele reputa também a Berkeley.

Segundo a análise desenvolvida por Bergson em Matéria e memória, o problema da percepção da matéria adviria do fato de que realismo e idealismo, no qual Berkeley é nominalmente incluído, partem justamente da distinção entre a percepção e a natureza mesma da matéria: "Em uma palavra, consideramos a matéria

ni virtualités d'aucune espèce. Qu'elle est étalée en surface et qu'elle tient tout entière, à tout instant, dans ce qu'elle donne". 
antes da dissociação que o idealismo e o realismo operaram entre sua existência e sua aparência".3

Segundo o vocabulário da filosofia moderna, a matéria existiria como extensão, no espaço; sua percepção existiria como representação inextensa, no espírito. Que ou a extensão no espaço ou a representação no espírito sejam a expressão do real, é o que cada sistema se esforçaria por provar. Nesse sentido, o idealismo de Berkeley negaria substancialidade à matéria porque não poderia conceber algo que fosse exterior ao espírito e que, por sua própria exterioridade, não pudesse ser intuído ou conhecido pelo espírito. Portanto, é a matéria dos realistas, considerada extensão no espaço, exterioridade distinta de sua representação interior ao espírito, que Berkeley levaria em consideração e cuja existência negaria. Mais uma vez, Berkeley partiria dessa distinção entre matéria e representação da matéria para negar um de seus polos. Sendo assim, negada a matéria como realidade exterior ao espírito, como extensão no espaço, o mundo material se resumiria ao mundo sensível, a matéria a um conjunto de sensações ou representações em uma mente, a ideias que, por sua peculiaridade mesma, seriam totalmente dadas ao espírito. No entanto, essa forma de fazer a matéria coincidir com aquilo que dela percebemos está, segundo Bergson, fundada em uma distinção inicial - ainda que posteriormente negada - entre a matéria e sua representação; isso equivaleria, em última análise, à anulação da matéria como realidade independente, uma vez que ela só existiria como representação em um espírito. Ou seja, é porque eu parto da distinção entre algo que existe independentemente e é inacessível em si - a substância material - e algo que só existe na mente e é diretamente acessível nas impressões sensíveis causadas por essa substância que, ao me opor à falta de acessibilidade da matéria, portanto à impossibilidade de

3 Bergson 1, p. 2. Apesar disso, Berkeley foi explícito em afirmar o contrário: "A distinção entre uma ideia e a percepção da ideia tem sido uma das maiores causas de se imaginar a substância material” (Berkeley 3, PC, p. 609 e Dialogues, p. 194-197). 
conhecê-la, eu automaticamente a nego como realidade que existe independentemente do espírito. Portanto, segundo Bergson, para negar a impossibilidade do conhecimento, ou, como sabemos, para se armar contra o ceticismo, Berkeley teria sido obrigado a negar a substancialidade da matéria ou sua existência independente do espírito, mas isso somente porque ele seria caudatário, ainda que de início, da concepção que afirma a dupla realidade da matéria.

Tomemos agora a concepção de matéria defendida por Bergson. Nela a matéria não deve ser considerada como aquela extensão em si mesma impossível de se dar na percepção sensível, e que, portanto, se daria apenas por representação em estados inextensos de uma mente. Em vez disso, já de início, a matéria deve ser considerada como aquele conjunto de imagens próprio à experiência sensível, algo que, por definição, pode ser ao menos parcialmente apreendido por uma consciência. Nessa hipótese, então, não existiria mais diferença de natureza entre a matéria e a percepção da matéria, ou dificuldade em explicar como duas realidades opostas podem se encontrar na percepção ou na consciência da matéria.

Ainda que não haja distinção de natureza, Bergson mantém a distinção entre a matéria e a percepção da matéria em outro nível: ele mantém a independência da matéria em relação àquela realidade que se distingue dela, que atua sobre ela ou que dela tem consciência, a que chamamos de espírito. Sendo assim, se Bergson nega, contra os dualistas clássicos, a distinção ontológica entre a matéria e a matéria percebida, nega também, e agora contra o imaterialista Berkeley, uma redução da matéria à matéria percebida. Nesse sentido, ele nega igualmente a dependência da matéria em relação à experiência da percepção ou àquele que a percebe.

Ao apresentar sua concepção de matéria como "imagem", no prefácio à sétima edição de Matéria e memória, Bergson a aproxima da concepção do senso comum, cujo estranhamento em relação às concepções que ele combate são descritas da seguinte maneira: 
Causaríamos muita surpresa a um homem sem familiaridade com as especulações filosóficas se lhe disséssemos que o objeto que ele tem diante de si, que ele vê e que ele toca só existe em seu espírito, ou mesmo, de um modo mais geral, só existe para um espírito, como quer Berkeley. Nosso interlocutor não deixaria de sustentar que o objeto existe independentemente da consciência que o percebe. Mas, de outro lado, igualmente o surpreenderíamos se disséssemos a ele que o objeto é totalmente diferente daquilo que ele percebe, que ele não tem nem a cor que o olho lhe confere nem a resistência que a mão nele encontra. ${ }^{4}$

Assim, segundo o próprio Bergson, para negar com Berkeley a existência de um objeto que "não tem nem a cor que o olho lhe confere nem a resistência que a mão nele encontra", não seria preciso reduzir o objeto a uma ideia ou sustentar que ele não existe "independentemente da consciência que o percebe".

Como vemos, ligada à peculiaridade da redução dos objetos às ideias, com a qual Berkeley nega a distinção de natureza entre a matéria e a percepção da matéria, surge a questão da dependência ou independência da matéria em relação ao sujeito da percepção. Essas questões devem ser abordadas para que, em suas inter-relações, possamos melhor determinar o sentido por elas constituído e, finalmente, determinar em que medida, por essa redução, a subjetividade dos dados dos sentidos para Berkeley não pode ser considerada no mesmo sentido daquele afirmado nas teorias da representação. Por oposição, delimitaríamos o tipo de objetividade que lhe é concedida.

\section{O sentido da "redução" berkelianista}

Especifiquemos, então, a dificuldade em distinguir a filosofia de Berkeley das teorias da representação, atendo-nos agora à estratégia 
por ele adotada de apresentar seu imaterialismo, no primeiro parágrafo da Parte I dos Princípios (Berkeley 3), com um texto que nos remete diretamente ao empirismo lockiano. Essa estratégia, se teve por objetivo ganhar a simpatia dos adeptos dessa doutrina ou realçar a perspectiva empirista como ponto de partida comum, levou também a muitos enganos. Entre eles, justamente, o de considerar a filosofia de Berkeley como uma radicalização ou um desenvolvimento natural do argumento de Locke segundo o qual as qualidades secundárias existiriam somente como dados subjetivos em uma mente. Tal radicalização seria levada a cabo pela afirmação da indistinção ontológica entre essas qualidades secundárias e as primárias; afirmação que, em última instância, estaria fundamentada na crítica berkelianista à capacidade da abstração. Se é impossível admitir a existência de uma extensão sem cor ou forma, ou do movimento sem corpo movido - o que implica a mudança de posição entre extensões coloridas com formatos definidos e, como tudo isso, extensões, formas, cores, movimento etc. são conteúdos que se dão a uma mente -, então, onde estaria o índice da tal existência que se furtaria a essa percepção e que, portanto, estaria fora da mente?

No entanto, ao raciocinarmos desse modo e colocarmos Berkeley como um passo a mais dado na história da filosofia a partir de Locke, corremos o risco de deixar escapar a intenção principal desse movimento. Pois, ao "subjetivar" também as qualidades primárias, ou seja, ao explicar as qualidades consideradas por Locke como existentes nas coisas exteriores em termos apenas de qualidades sensíveis, Berkeley efetua muito mais do que uma radicalização de pressupostos. Parece mesmo que Berkeley se desfaz, aqui, do princípio ontológico subjacente: ele acaba por se desfazer da referência exterior que concede identidade e existência objetiva ao que é percebido pelos sentidos e que, ao mesmo tempo, faz dessa percepção algo relativo. Assim, no mesmo movimento em que Berkeley suprime a tese da dupla existência do mundo físico, uma no interior e outra no exterior da mente, ele suprime o pressuposto ontológico da identidade 
dos objetos, subjacente à necessidade de relegar à percepção a variabilidade que não se coaduna com essa identidade imutável. Sendo assim, reduzindo aquilo que é caracterizado como espacialidade a percepções de uma mente, não é o acesso ao exterior que se vê bloqueado, mas a própria existência de uma exterioridade material.

Se assim for, a redução das qualidades primárias ao universo mental, em Berkeley, se dá por razões e num sentido diferente daquele da filosofia da representação como um todo e da distinção de Locke em particular. Para estes, que tinham o objeto uno exterior como ponto de fuga do conhecimento, as qualidades eram subjetivadas ou entendidas como percepções que se davam no interior de sujeitos particulares, pela necessidade de acomodar a grande variedade dessas qualidades e os conceitos de identidade e permanência que caracterizam esse objeto exterior. Pois, os argumentos céticos contra a fidedignidade dos sentidos estavam na ordem do dia, problematizando a possibilidade de conhecimento, e era preciso refutá-los. Para Berkeley, ao contrário, a redução das qualidades dos objetos físicos ao universo mental não se dá por sua relatividade - mesmo porque não há tal relatividade quando não há o parâmetro do objeto exterior. Em vez disso, há simplesmente a identificação absoluta entre essas qualidades, que se caracterizam justamente por serem perceptíveis para uma mente, e o objeto. E essa identificação só é possível, porque o que foi problematizado, agora, é o pressuposto da identidade exterior. Assim, Berkeley não tem em muita conta os argumentos céticos contra as ilusões dos sentidos, uma vez que esses argumentos só funcionariam se considerado o pressuposto que agora está em questão. Com efeito, nos Princípios, quando ele os utiliza para mostrar sua possibilidade de aplicação também às qualidades primárias (Berkeley 3, PHK, $\$ 14$ ), logo reconhece sua pouca serventia, porque tais argumentos "não provam que não há extensão ou cor em um objeto exterior, mas que não podemos saber pelos sentidos qual a verdadeira extensão ou cor do objeto" (Berkeley 3, PHK, $\$ 15)$. E ele acrescenta: “mas os argumentos acima mencio- 
nados mostram plenamente que é impossível que qualquer cor ou extensão, ou qualquer outra qualidade sensível possa existir em um objeto não-pensante fora da mente, ou, na verdade, que possa haver algo como um objeto exterior" (Berkeley 3, PHK, $\$ 15$ ). Portanto, a redução do físico ao mental, pretendida por Berkeley, se dá segundo um argumento que se distingue daqueles apresentados pelos céticos e aos quais os modernos procuraram responder - alguns assumindo a relatividade de determinadas qualidades dos objetos pela subjetivação destas e pela consequente distinção entre o objeto físico e sua percepção por uma mente. E que argumento seria este? Justamente o da redutibilidade de todo objeto - aquele que é percebível imediatamente pela visão, audição, tato, olfato e paladar - a qualidades sensíveis. Não se trata de um argumento propriamente dito, mas, segundo Berkeley, de um conhecimento intuitivo, da evidência do princípio fundador de sua doutrina, segundo o qual o ser das coisas — e como "coisas" devemos entender tudo que não é espírito - está dado naquilo que se percebe delas. Isso expressa a evidência da identidade entre existência física, material, sensível, como queiramos, e percepção ou, se nos permitirem, modos da percepção (Berkeley 3, PHK, \$3). E não foi o que Berkeley disse desde o início ao afirmar o esse é percipi como princípio de seu imaterialismo? Não é por acaso que, logo no primeiro parágrafo dos Princípios, Berkeley tenha enumerado esses sentidos e as qualidades a eles correspondentes e tenha deixado explícito que os objetos são constituições que não vão além dessa coleção de qualidades. ${ }^{5}$

Quando se trata de objetos, aqueles que são imediatamente percebidos pelos sentidos, e Berkeley insiste em se colocar de acordo com seu interlocutor a esse respeito ${ }^{6}$, tudo se reduz aos modos possíveis

5 Berkeley 3, PHK, \$1: “Assim, por exemplo, observados em conjunto certa cor, sabor, cheiro, figura e consistência, foram considerados uma coisa distinta, significada pelo nome maçã".

6 "Pois o que são os objetos acima mencionados além de coisas que percebemos pelos sentidos, e o que percebemos além de nossas próprias ideias ou sensações; e não repugna 
dessa percepção. Não há nenhuma característica positiva que possamos dar ao mundo físico que não se resolva nos elementos aos quais temos ou podemos ter acesso pelos sentidos. Não há nada nessa percepção - nenhuma extensão, nenhuma forma, nenhum movimento - que remeta a uma substância inerte que lhe seja semelhante ou substrato, e que não seja, também, passível de ser reduzido a sensações. Do mesmo modo, também não há qualquer possibilidade de algo inativo ser causa do que quer que seja - no caso, de sensações.

Por outro lado, uma vez que Berkeley parte da evidência desses objetos dos sentidos, evidência que reside exatamente no fato de serem conteúdos imediatamente apreendidos, nada que fosse menos evidente que eles próprios poderia pôr em risco sua realidade. Mas é justamente o que ocorre. A hipótese de um objeto exterior e imediatamente inacessível põe em questão a realidade daquilo que é imediatamente dado. ${ }^{7}$ Há, então, que revelar o caráter insustentável dessa hipótese, de qualquer forma que ela nos tenha sido apresentada,

que uma ou uma combinação delas possam existir impercebidas??. In: Berkeley 3, PHK, $\S 4$; DHP, p. 174.

7 Berkeley 3, PHK, $\$ \$ 87,88$. “Cor, figura, movimento, extensão e outras, consideradas apenas como sensações na mente, são perfeitamente conhecidas, nelas nada é impercebido. Mas consideradas notas ou imagens que se referem a coisas ou arquétipos existentes fora da mente, arrastam-nos ao ceticismo. Temos as aparências e não a realidade das coisas. Que sejam extensão, figura, movimento ou alguma coisa real e absolutamente ou em si não podemos sabê-lo, mas somente a sua proporção ou relação com os nossos sentidos. Permanecendo iguais as coisas e variando as nossas ideias, não alcançamos determinar qual das ideias ou se alguma representa a verdadeira qualidade da coisa. E assim tudo quanto vemos, ouvimos e sentimos pode ser fantasma ou quimera vã, e não se ajustar com as coisas reais da nossa rerum natura. Todo esse ceticismo provém de supor uma diferença entre coisas e ideias e que as primeiras subsistem fora da mente ou impercebidas. Fácil fora alongar esse assunto e mostrar como os argumentos dos céticos dependem sempre da suposição de objetos externos. (...) Supondo a existência real de seres impensantes, diferentes de serem percebidos, não só nos é impossível conhecerlhes a natureza mas até saber que existem. Por isso vemos filósofos duvidarem dos sentidos, duvidarem da existência do céu e da terra, do que veem ou sentem e até de seu próprio corpo. E depois dessa faina e luta de pensamento, são forçados a reconhecer a dificuldade de alcançar conhecimento demonstrativo e evidente da existência das coisas sensíveis. (...)" 
ainda que, como o próprio Berkeley nos diz, isso não fosse realmente necessário se nos ativéssemos à evidência do princípio anterior, e se não tivéssemos obscurecido a claridade de tal evidência com camadas e camadas de "poeira sábia" que, então, fosse preciso remover.

E é para remover essas camadas de poeira que Berkeley responde a cada um dos argumentos apresentados pelos materialistas, argumentos que se baseiam no raciocínio segundo o qual sem a pressuposta existência exterior à mente o mundo físico percebido por essa mente perderia sua objetividade; em outras palavras, os objetos dos sentidos perderiam sua realidade. Berkeley refuta tais argumentos expondo as inúmeras falácias e contradições que a hipótese do objeto exterior implica; ele afirma que, ao contrário, a realidade do mundo físico é dada na apreensão direta dos vários aspectos dos objetos sensíveis percebidos pelas mentes.

É assim que Berkeley explora à exaustão as falácias que se seguem à pressuposição da realidade exterior. $\mathrm{E}$, a cada exame, sua posição inicial é reafirmada e se distingue tanto da dos filósofos modernos quanto da dos céticos, que, para ele, são semelhantes em sua suposição da dupla existência do objeto, com o que impossibilitam nosso acesso à realidade do mundo e, portanto, impossibilitam o conhecimento. Examinemos, então, alguns momentos em que esse embate de razões se explicita e vejamos que esclarecimentos eles podem nos dar em relação à face crítica do imaterialismo de Berkeley.

\section{Hilas e Filonous}

Passemos à reconstrução das linhas gerais pelas quais Berkeley examinará, nos Três Diálogos entre Hilas e Filonous, vários argumentos apresentados pelos materialistas em defesa da existência de um objeto exterior à mente.

Ao final da longa argumentação em favor de reduzir as qualidades tanto primárias quanto secundárias ao universo da percepção, na primeira parte do Primeiro Diálogo (Berkeley 3, DHP, p. 171-194), 
Berkeley iniciará uma crítica retrospectiva das hipóteses apresentadas em favor da existência exterior do objeto, ou seja, de sua existência para além dos limites desse universo perceptível. Essas hipóteses teriam sido apresentadas sem levar em conta a redução radical que acaba de ser efetuada e, nesse sentido, continuariam afirmando uma distinção entre o objeto material e a percepção sensível do objeto, esta na mente e aquele exterior à mente. Com efeito, após ter aceitado a argumentação de Filonous em favor da inseparabilidade das qualidades primárias e secundárias pela admissão de que se estas estão na mente (Locke) aquelas também estarão, Hilas - o oponente materialista do imaterialista Filonous - se ressente de que, assim fazendo, estaria negando realidade a essas qualidades sensíveis e, portanto, ao mundo físico em geral. Desse modo, para garantir a realidade do mundo físico, Hilas retrocede na argumentação e lança mão, num movimento antilockiano, da distinção entre a real existência das qualidades sensíveis nas coisas e sua percepção, por uma mente, que se daria por um ato. Assim surge, como um primeiro fundamento da suposição da dualidade a ser examinado, o de uma atividade do espírito que seria a sensação, nele, daquilo que existiria realmente no objeto: "H. - Por exemplo, há vermelho e amarelo nesta tulipa. Mas o ato de perceber essas cores está em mim apenas, e não na tulipa" (Berkeley 3, DHP, p. 194).

Tentando recuperar com seu interlocutor a redução que acabaram de fazer, Filonous argumenta que a tulipa, enquanto objeto da visão - e, nesse sentido, nada mais do que uma extensão que coexiste com uma determinada cor e forma ${ }^{8}$-, só pode existir como uma visão, em uma mente, ainda que se deva admitir que essa visão seja independente de uma ou outra mente em particular. Assim, dizer que há algo que está na tulipa e não está na visão da tulipa, e que, portanto, não está em uma mente, é um contrassenso (Berkeley 3, DHP, p. 195). No entanto, uma vez que a redução já havia

8 Berkeley 3, DHP, p. 195: "F. - O que você quer dizer é que o vermelho e o amarelo coexistem com a extensão, não é?”. 
sido abandonada por Hilas, como mostra a própria distinção por ele proposta, Berkeley não se furtará a procurar outros caminhos para comprovar as conclusões anteriores. Decide-se, então, a examinar - sem levar em conta ele também a redução feita anteriormente - qual seria a atividade existente na sensação que poderia distingui-la do objeto sentido e a partir da qual se poderia afirmar a real existência das qualidades sensíveis fora da mente em uma substância não pensante (Idem, ibidem). No entanto, a análise da percepção das cores e dos perfumes leva Filonous e Hilas a concluir que, se há alguma atividade implicada na percepção, esta é apenas aquela de uma vontade que a antecede, possibilitando-a, mas que a própria percepção é totalmente passiva:

F.: - Assim, não está em seu poder abrir os olhos, ou mantê-los fechados; dirigi-los para um lado ou outro? (...) Mas depende igualmente da sua vontade, ao olhar esta flor, perceber branco ao invés de qualquer outra cor? Ou, ao dirigir seus olhos abertos para a imensidão do céu, você pode evitar ver o sol? Ou ainda, seriam a luz e a escuridão efeitos de sua vontade? (...) Em relação a isso você é totalmente passivo (Berkeley 3, DHP, p 196)

Hilas, no entanto, mesmo não podendo deixar de concordar com o caráter passivo da percepção, não se atreve a assumir a conclusão do seu argumento e afirmar que tal percepção, passiva, reside em uma substância externa insensível. Para Filonous, tal passividade que está no objeto percebido e na percepção, dado que são uma e a mesma coisa, é mais um signo da indistinção entre a percepção e objeto sensível ou entre as ideias e as coisas. Com efeito, a atividade, no conjunto da doutrina de Berkeley, não será aquilo que distingue a percepção do objeto percebido, mas o ser que percebe de sua percepção, ou, se quisermos, o espírito do mundo sensível (distinção a que retornaremos adiante). 
Prosseguindo em sua "faxina" epistemológica, Filonous-Berkeley examinará o próximo argumento materialista apresentado por Hilas. Este, em mais um esforço para conceder realidade exterior às coisas sensíveis, levanta uma segunda hipótese: considerando tais coisas sensíveis como modos ou qualidades, estas teriam necessariamente sua realidade dependente de um substratum material (Berkeley 3, DHP, p. 197-199). No entanto, por meio de uma análise semântica, Filonous faz ver a Hilas que o termo substrato, tanto considerado como suporte quanto como substância, só tem sentido em sua significação literal, ou seja, aquela que necessariamente remete às qualidades sensíveis implicadas nas definições dos termos, remetendo a “estar sob, subjazer". Assim, para estar sob as qualidades sensíveis e, o que importa para Hilas, para além delas, seria preciso, ao menos em relação aos objetos visíveis, estar sob a extensão visível. Mas como é possível estar sob a extensão sem ser também extenso? E se tal acepção do termo é por demais prosaica, é possível conceder-lhe outra? Filonous acredita que não, e Hilas não consegue apresentar-lhe nada que o convença do contrário.

Lembremo-nos a esse respeito das considerações sobre a linguagem que fazem parte do método berkelianista e que denunciam os erros inerentes ao fato de usarmos determinada palavra, acreditando que ela se refira a uma ideia, quando não se refere à ideia alguma. Isso ocorre com os termos suporte ou substância quando fazem parte da definição de matéria como substratum de acidentes. Se quisermos usá-los para provar a necessidade da existência de algo exterior à mente, é porque acreditamos que seu significado nos remete a essa existência exterior. No entanto, de acordo com os parâmetros nominalistas de significação, defendidos por Berkeley, tais termos só têm significado se os relacionarmos a ideias sensíveis, justamente o que se queria evitar, uma vez que só podemos compreender o sentido de "estar sob, subjazer, suportar" remetendo-nos à ideia sensível de extensão. Segundo Filonous, no entanto, nenhuma dessas considerações teria sido necessária se Hilas tivesse atentado para o fato ab- 
soluto da existência das qualidades sensíveis e que sua realidade não pode depender da suposição de um suporte material, uma vez que tais qualidades sensíveis são dadas imediatamente e tal suporte não é dado nem imediata nem mediatamente. Ou seja, Hilas deveria ter atentado para o absurdo que consiste em dar realidade às qualidades sensíveis por meio de um fundamento inconcebível dessa realidade. É assim que Filonous chama a atenção de Hilas:

(...) você afirmou que não poderia conceber como qualidades ou acidentes poderiam existir realmente sem conceber, ao mesmo tempo, um suporte material para eles. (...) Quer dizer, quando você concebe a existência real das qualidades, concebe ao mesmo tempo algo que não consegue conceber. (Berkeley 3, DHP, p. 199)

O tema da conceptibilidade é retomado uma vez mais quando, na sequência da argumentação, Hilas lança mão do que acredita ser uma terceira possibilidade de fundamentação da existência de qualidades sensíveis exteriores ao espírito. Ele propõe que o problema dessa existência esteja na abordagem de cada uma das qualidades separadamente, o que não ocorreria se elas fossem tomadas em conjunto (Berkeley 3, DHP, p. 200). Nessa terceira recaída de Hilas, Filonous perde um pouco a compostura e o acusa de não estar sendo sério. Afinal, eles já haviam concluído, entre outras coisas, que as qualidades secundárias só podem existir umas unidas às outras e em uma mente, onde também estariam as qualidades primárias. Seria impossível considerar que estas são separadas daquelas, ou seja, concebê-las de modo distinto daquele de uma percepção possível. O fato - e é o que nos interessa aqui - é que Filonous propõe deixar de lado toda a sua argumentação anterior e aceitar o ponto de vista de Hilas sobre a existência de objetos exteriores à mente se ele assim puder conceber um deles que seja. ${ }^{9}$ Hilas responde que não há tarefa

9 Berkeley 3, DHP, p. 200: "Se você puder conceber que qualquer mistura ou combinação de qualidades, ou qualquer objeto sensível, possa existir fora da mente, então eu concor- 
mais fácil, uma vez que é perfeitamente possível conceber árvores e casas existindo sem que haja alguém para percebê-las. A isso, Filonous retruca com a explicitação da incoerência na fala de Hilas, que afirma a existência de coisas exteriores à mente no momento mesmo em que ele as têm em sua própria mente, ao concebê-las impercebidas. Mais uma vez, portanto, Berkeley está afirmando a força de seu princípio, que bastaria por si só para sustentar o seu imaterialismo. Afinal, o que significa a impossibilidade de conceber árvores no parque sem serem percebidas senão a impossibilidade de conceber árvores impercebíveis, ou seja, não determinadas por aquele conjunto mínimo de qualidades que compõe a experiência de uma árvore e que dá sentido a esse termo "árvore"?

Mas há ainda, entre essas tentativas de firmar um sentido para a hipótese da existência de objetos exteriores, aquela que esbarra numa dificuldade que vai além desta ou daquela caracterização da matéria como realidade espacial distinta das formas de sua percepção. Tratase da dificuldade com a qual todos os dualismos representacionistas têm de lidar no que se refere à gênese da representação, a um certo "mecanismo" que dê conta da ação da matéria sobre o espírito no momento da produção das ideias sensíveis. Levando tal dificuldade em conta, Berkeley irá desenvolver, logo no início do Segundo Diálogo, uma versão anterior daquela crítica retomada por Bergson em Matéria e Memória, e que se baseia na falta de sentido em considerar o cérebro, ideia entre ideias - ou, como quer Bergson, imagem entre imagens -, como produtor de ideias.

Sigamos a apresentação da hipótese por Hilas:

H.: Supõe-se que a alma resida em alguma parte do cérebro, na qual os nervos se originam e de onde se estendem para todas as partes do corpo; e que objetos exteriores, pelas diferentes impressões que fazem nos órgãos dos sentidos, comunicam certos movimentos vibratórios aos nervos, que, 
estando repleto de espíritos animais, os propagam até o cérebro ou sede da alma, a qual, de acordo com as várias impressões ou traçados feitos por esse modo no cérebro, é afetada por diferentes ideias.

Ao que Filonous responde, não sem antes ter se certificado com Hilas de que o cérebro ao qual ele se refere é uma coisa sensível e, portanto, imediatamente perceptível:

F.: Além dos espíritos, tudo que conhecemos são nossas próprias ideias. Portanto, quando você diz que todas as ideias são ocasionadas por impressões no cérebro, você concebe ou não esse cérebro? Se concebe, então você fala de ideias impressas em uma ideia, causando aquela mesma ideia, o que é absurdo. Se você não concebe, você fala ininteligivelmente, sem formar qualquer hipótese razoável. (Berkeley 3, DHP, p. 208-209)

É evidente, portanto, que o modelo representacionista é aqui criticado. Se nervos e cérebro só podem ser entendidos enquanto extensões determinadas por formas, cores e texturas, é porque são impressões de uma mente. Como, então, essas impressões poderiam causar todas as demais impressões dessa mente? $\mathrm{Ou}$, ainda, como poderiam elas causar o que quer que seja, dada sua natureza inativa? Aqui, a comparação pontual com Bergson parece profícua para demonstrar a força do argumento. Que os nervos e o cérebro sejam considerados ideias interiores a uma mente ou imagens exteriores tornadas conscientes pela ação de uma mente, eles são, de qualquer modo, da mesma "natureza" dos demais objetos físicos, por meio dos quais, portanto, estes não podem ser dados ou neles estarem contidos.

Examinados os argumentos em favor da concepção da matéria para além de sua caracterização por aquilo que é passível de ser percebido, conclui-se o caminho de supressão da exterioridade, concebida nos moldes das teorias da representação, caminho iniciado pela redução berkelianista das coisas às ideias. No entanto, esse novo 
campo das ideias que então se esboçou não pode, como sustentamos anteriormente, ser confundido com o da interioridade que também caracteriza os sujeitos. A distinção entre exterioridade e interioridade tem de ser mantida na medida mesma em que as ideias sensíveis, para Berkeley, se distinguem dos espíritos aos quais elas são, no entanto, acessíveis de modo imediato. E aqui é a própria constituição dessa nova exterioridade que demanda um novo sentido da interioridade. ${ }^{10}$ Esta não pode mais ser o domínio de introspecção de um sujeito, mas se transforma no ambiente acessível a qualquer sujeito e independente de cada um deles em particular. Assim, imediatamente após a redução das coisas às ideias, surge a necessária presença de uma consciência onipresente na qual todas essas ideias ganhariam objetividade. Não se trata mais, como já vimos, daquela objetividade da coisa una à qual nossas variadas representações remeteriam, mas a objetividade que é, eminentemente, independência dos dados dos sentidos em relação ao sujeito que os percebe, e que se insere, portanto, nas próprias "representações" que, em conjunto, formam um objeto. Assim, após termos visto como Berkeley nega a hipótese da causação das ideias segundo o modelo acima exposto, examinemos sua própria hipótese casual, pelo que seremos levados à questão anteriormente apontada da independência destas ideias-coisas em relação aos sujeitos da percepção.

\section{A objetividade das coisas percebidas}

Para sustentar a distinção de sentido entre a subjetividade inerente à teoria da representação e aquela apresentada pelo imaterialismo de Berkeley, com sua noção correlata e oposta de objetividade, somos levados agora a examinar a hipótese berkelianista da causa mesma dessas percepções, hipótese que garante que elas não perderam seu estatuto de coisas percebidas. Como vimos, não há

10 Há, a esse respeito, inúmeras questões e dificuldades que não serão aqui tratadas, por não serem passíveis de desenvolvimento no âmbito deste trabalho. 
para Berkeley um ato de percepção que se oponha ao seu conteúdo, e isso porque a percepção propriamente dita não envolve um ato, mas um agente que, no momento da percepção, é passivo. Portanto, percepção e conteúdo da percepção formam uma unidade impossível de ser distinguida e cuja realidade não pode ser contestada, por se tratar de uma apreensão imediata. Se é assim, se a percepção e o que é percepcionado não podem ser distinguidos, e se pressupõem um agente no qual ocorram, não há nada que sustente a hipótese de uma substância inativa a partir dessa percepção, uma vez que tal substância introduziria uma distinção que se mostrou inconcebível. Por outro lado, a passividade da percepção, que aponta para a inatividade do sujeito ativo no momento da percepção, pode ser explicada por um outro Ser Ativo, de maior potência, que age sobre aquele ser ativo de menor potência. E é desse modo que propomos a leitura da passagem que se segue, no Segundo Diálogo, às examinadas acima. Passagem na qual Filonous, a partir da inatividade do espírito que percebe e da independência daquilo que percebe em relação a sua vontade, afirma a existência de outro espírito mais poderoso que explicaria a realidade dada dessas coisas percebidas. Assim, após reafirmar a realidade das percepções e do mundo físico que elas constituem, pela descrição que enfatiza a evidente superioridade de escala entre essas ideias sensíveis e aquelas que qualquer espírito finito pudesse suscitar (Berkeley 3, DHP, p. 210-211), Filonous conclui pela existência de Deus.

F.: Para mim é evidente, pelas razões às quais você deu assentimento, que as coisas sensíveis não podem existir em outro lugar a não ser em uma mente ou espírito. Do que eu concluo, não que não tenham existência real, mas que, ao ver que não dependem do meu pensamento, e que existem independentemente de serem por mim percebidas, deve haver alguma outra mente na qual elas existem. Portanto, tão certo quanto a existência real do mundo sensível, é a de um espírito onipresente que o contém e suporta. 
Mas, isso não é o que também supõe qualquer filósofo que assuma a existência de um princípio criador, origem e fundamento de tudo que existe, matéria ou espírito, ou seja, quando esse espírito do qual a matéria depende é Deus? É o que o próprio Hilas retruca:

H.: Ora, mas isso é o que eu e todos os cristãos sustentamos! Mais do que isso, é o que sustentam todos aqueles que acreditam que há um Deus, e que ele conhece e abarca todas as coisas.

No entanto, Filonous faz notar uma distinção fundamental:

F.: Mas é justamente nisso que reside a diferença! Os homens geralmente acreditam que todas as coisas são conhecidas e percebidas por Deus porque acreditam que há um Deus, enquanto eu, ao contrário, concluo imediata e necessariamente a existência de Deus porque todas as coisas têm de ser percebidas por ele. (Berkeley 3, DHP, p. 212)

E aqui se apresenta o que podemos considerar como mais uma oposição em relação às posições assumidas pela filosofia moderna. Agora, trata-se especificamente de uma crítica à necessidade da prova da existência de Deus em Descartes. Ora a filosofia que afirma a independência da matéria em relação ao espírito não é, pois, aquela que tem de provar a existência de Deus para então garantir a realidade do mundo físico? E não é justamente o imaterialista Berkeley que, ao contrário, nos oferece uma prova da existência de Deus a partir da realidade do mundo físico? Estamos diante de um simples jogo de cena, ou os papéis se mostram invertidos quando os parâmetros do pensamento começam a se alterar em relação ao que os precedia?

De fato, entra em jogo aqui uma possível problematização levantada (Fleming 4) justamente em relação a essa passagem que pode ser reconstruída do seguinte modo: Berkeley parte da observação de que não é causa de suas ideias sensíveis, passa pela afirmação de que elas existem independentes de sua mente e, por fim, chega à conclusão de 
que há outra mente na qual elas existem. Com efeito, o terceiro passo poderia ser considerado anterior ao segundo, ou seja, eu não poderia afirmar a existência exterior ou independente das ideias sensíveis se não pressupusesse que elas existem em outra mente e que, portanto, existem na mente de outro espírito etc.

No entanto, parece-me que a hipótese de que as ideias existem na mente de Deus (3) é posterior tanto à observação de sua independência (2) quanto ao fato de não serem causadas por mim (1). Afinal, entre (2) e (3) há a hipótese de que essa independência das percepções seja sinal justamente da distinção entre essa percepção e aquilo que é percepcionado e que estaria em uma substância não pensante exterior ao espírito. Esta é, aliás, a hipótese materialista que deve ser afastada para que (3) se evidencie como a verdadeira. Isso é feito pela demonstração da inconceptibilidade dessa substância exterior não pensante, uma vez que, por um lado, é impossível darlhe qualquer conteúdo positivo, como o de extensão ou movimento no espaço, dado que a inteligibilidade desses conceitos depende de sua redução a conteúdos sensíveis, portanto, no âmbito do universo mental; por outro lado, é impossível dar-lhe qualquer conteúdo relacional, dado que, na noção de suporte, está implícita a de extensão, e então cairíamos no caso acima. A última possibilidade seria considerá-la como causa - o que, no entanto, implicaria uma atividade, que só poderia ser encontrada em uma mente e não em uma substância inerte. Assim, parece bastante plausível sustentar que, no âmbito da argumentação desenvolvida por Berkeley, a afirmação da existência de Deus como suporte do mundo sensível não seria anterior, mas posterior ou, no máximo, concomitante ao fato de não estar envolvida na percepção sensível a vontade do ser que percebe e da impossibilidade de que essa percepção sensível seja causada por uma substância não pensante.

Resta um último ponto em relação a essa objetividade concedida pela mente divina aos objetos do mundo físico na filosofia de Berkeley: seria possível afirmar, com base nas passagens em que Berkeley 
se refere à existência dos objetos sensíveis na mente de Deus, que tais objetos seriam pensados por Deus e, de algum modo, acessados pelos espíritos finitos, e não que seriam apenas causados por Deus diretamente na mente desses seres finitos. Com efeito, se admitíssemos essa última hipótese, o mundo físico seria apenas causalmente independente dos espíritos finitos e não existencialmente dependente, como assegura a hipótese que defendemos segundo as próprias palavras de Berkeley:

(...) Pois ainda que tenhamos afirmado que os objetos dos sentidos nada mais são que ideias que não podem existir impercebidas, no entanto, não se pode concluir daí que só tenham existência quando são percebidos por nós, uma vez que pode haver algum outro espírito que os perceba enquanto nós não os percebemos... (PHK, Parte I, $\$ 454$ 48)

(...) consequentemente, quando não são percebidos por mim, e não existem na minha mente ou na de qualquer outro espírito criado, ou não existem de modo algum ou subsistem na mente de um espírito eterno. (...) Há, portanto, alguma outra mente na qual elas existem, durante os intervalos de tempo que se interpõem entre minha percepção delas: quando elas eram percebidas antes de meu nascimento, e deverão ser depois de meu suposto aniquilamento. (Berkeley 3, PHK, Parte I, $\$ 6$; DHP, p. 231)

Sendo assim, nem o mundo físico - ou, se quisermos, a matéria - é subsumido ao espiritual, nem o espiritual pode ser confundido com a matéria. A "matéria" - esse conjunto de ideias - é uma realidade, e se distingue do espírito, mas interage com ele ou porque é por ele gerada ou porque é por ele acessada em sua própria realidade. Ou então, para não ferirmos o espírito da letra de Berkeley, a matéria é a natureza, esse conjunto de ideias que Deus concebeu para se comunicar com sua dileta criatura; por isso, ela existe para a sua criatura. Nada nela é em princípio 
inacessível à sua criatura, que, por ser imagem e semelhança de seu criador, é essencialmente espírito.

Levando isto em conta, voltemos a considerar a questão da dependência da matéria em Berkeley: esta se dá em relação ao Espírito, em relação ao qual também os espíritos finitos são dependentes. Ambos são dependentes, ainda que de formas diferentes, e ambos existem, ainda que também de formas diferentes, mas é nessa diferença mesma de formas de existência, quer dizer, de naturezas, que eles podem se encontrar. Assim, ainda que Berkeley não se canse de afirmar a dependência das ideias - ou seja, das coisas - em relação à mente, para ele essas coisas não são criadas pelos sujeitos que as percebem e não desapareceriam se um determinado sujeito de sua percepção desaparecesse. Esse mundo das coisas sensíveis extrapola, na medida da infinitude divina, a percepção de um sujeito, de todos os sujeitos finitos reunidos, dado que "subsistem na mente de um espírito eterno"."1

Portanto, se Berkeley afirma que o mundo físico é um conjunto de ideias e que, sendo assim, só pode existir em uma mente, mas ao mesmo tempo, ele assume que há mais ideias do que as que a mente ou que o conjunto dos espíritos finitos pode perceber — uma vez que elas existiriam como obra de Deus passível de ser percebida — podemos defender a hipótese de que sua concepção da dependência desse mundo físico em relação às mentes que o percebem se resume exatamente nessa sua possibilidade de ser percebido, nessa sua possibilidade de ser acessado pelo espírito e, consequentemente, no fato de não escon-

11 Berkeley 3, PHK, $\$$ 6; ou ainda DHP, p. 231: "quando eu nego às coisas sensíveis uma existência fora da mente, não estou considerando minha mente em particular, mas todas as mentes. Pois é óbvio que elas têm uma existência exterior à minha mente, uma vez que pela experiência observo que são independentes dela. Há, portanto, alguma outra mente na qual elas existem, durante os intervalos de tempo que se interpõem entre minha percepção delas: quando elas eram percebidas antes de meu nascimento, e deverão ser depois de meu suposto aniquilamento. Verdade que se estende a todos os espíritos finitos; do que se segue necessariamente que há uma Mente eterna onipresente, que conhece e compreende todas as coisas, e que as exibe diante de nossa visão segundo os modos e de acordo com as regras por ele determinadas, as quais chamamos de Leis da Natureza”. 
der em si nenhuma realidade inacessível, quanto mais sua verdadeira realidade. ${ }^{12} \mathrm{E}$ nisto, principalmente, na impossibilidade de que uma realidade tão extremamente unida à nossa seja apenas um simulacro. Nessa acessibilidade, pelo espírito, da realidade até então chamada de material se fundaria sua nova denominação como ideia e a insistência em afirmá-la como existente em um espírito. Afirmação que, no entanto, não pode ser entendida em seu sentido espacial estrito. Segundo as próprias palavras de Berkeley,

quando eu falo dos objetos como existindo no espírito ou como impressos nos sentidos, não pretendo ser compreendido em sentido literal, como quando se diz que um corpo existe em um determinado lugar ou que um selo se imprime na cera. Quero apenas significar que a mente os compreende ou percebe; e que é afetada do exterior, ou por algum ser distinto dela. (PHK, \$250)

Ao entender dessa maneira o percipi de Berkeley, chegamos a uma caracterização do universo das ideias e de sua independência em relação aos sujeitos da percepção que guarda muitas semelhanças com o modo pelo qual Bergson concebe seu campo de imagens. Pois, para Bergson, a independência da matéria em relação ao sujeito de sua percepção se explicita justamente no fato de que o mundo material extrapola nossa percepção dele e existiria mesmo se não houvesse nenhuma consciência parcial dele. Mas ele existiria como imagem, ou seja, como algo que, mesmo impercebido, seria passível de percepção.

\section{Berkeley e Bergson}

Resolvida a questão da independência ou dependência da matéria em relação ao espírito nos termos da acessibilidade da realidade da

12 Com o que concordamos com a caracterização dada por Bergson, conforme citação anterior, ver nota 2. 
matéria, que aproximariam as concepções de matéria de Berkeley e Bergson, expressas nas figuras de "ideia" e "imagem", somos levados de volta à questão inicialmente apresentada: a discordância entre Bergson e Berkeley no que diz respeito ao "lugar" da percepção. A esse respeito, devemos considerar o seguinte: embora Bergson afirme que nossa percepção está nas coisas e Berkeley diga que nossa percepção só pode estar onde estão as ideias, ou seja, em um espírito, ambos consideram que as coisas, imagens ou ideias estão todas nesse campo de coisas, ideias ou imagens que transcende a esfera individual do espírito. Esfera individual que, mesmo sendo, um recorte ou uma perspectiva assumida pelo espírito no interior do campo que o transcende, apreende esse campo em sua própria natureza.

Portanto, quando Bergson afirma que a percepção está nas coisas percebidas e não na mente, ele nada mais está fazendo do que criticar essa distinção entre a matéria e sua representação. Afinal, essa distinção faz das percepções "alucinações verdadeiras", ou seja, estados do sujeito projetados para fora dele, quer sejam entendidos como a única realidade existente ou como apenas semelhantes a ela. Por outro lado, quando Berkeley afirma que todo o mundo sensível só pode existir em uma mente, nada nos autoriza a identificar essa mente àquela realidade inextensa que caracteriza cada sujeito individualmente, cujos estados seriam posteriormente exteriorizados e que, portanto, produziria representações à maneira de alucinações. Para Berkeley, mente significa tanto cada um dos sujeitos da percepção quanto aquela espiritualidade superior; percepção significa a consciência, por esses sujeitos, do mundo sensível, que, sustentado por aquela espiritualidade superior, é composto por realidades exteriores e acessíveis, em si mesmas, a cada indivíduo. Assim, a mesma identidade estabelecida por Bergson entre a percepção e as coisas percebidas é mantida em Berkeley, tal como a realidade dessas coisas percebidas como exterior a cada sujeito da percepção.

Pois não se trata aqui da distinção entre matéria e percepção da matéria, e a consequente divisão entre realidade material, exterior ao 
espírito, e realidade sensível, interior ao espírito, que Berkeley nega ao afirmar que o mundo físico se resume àquilo que pode ser percebido por uma mente? Afinal, isso que é percebido por uma mente nada tem a ver com estados da mente causados por uma substância exterior desconhecida e posteriormente exteriorizados como representações. Ora, Berkeley assume que o mundo físico se resume a ideias em uma mente; contudo, isso não significa que essas ideias são produzidas nessa mente. Elas são, sim, apreendidas pela mente a partir do exterior, porque é no exterior que está sua fonte, um espírito infinito que as apresenta. Nesse sentido, Berkeley não poderia dizer junto com Bergson que a percepção das coisas ocorre nelas mesmas, ou seja, que a percepção de uma ideia está na apreensão da própria ideia e não em uma duplicação, na mente, de uma realidade exterior?

E não poderíamos considerar que a afirmação de Bergson de que nossa percepção está nas coisas corresponde à afirmação de Berkeley segundo a qual tudo que percebemos só pode estar em uma mente? Afinal, entendemos essa mente como aquele campo de coisas, ideias ou imagens que transcende a esfera individual do espírito - esfera que, no entanto, ao se apresentar como um recorte ou uma perspectiva assumida por esse espírito no interior desse campo que o transcende, apreende-o em sua própria natureza.

Se essas considerações puderem ser confirmadas em seu desenvolvimento mais estrito, poderiam fortalecer a hipótese de que tanto Berkeley quanto Bergson figuram lado a lado em uma corrente de pensamento que rompe com a gnosiologia moderna, a qual é concebida a partir da distinção a priori entre duas substâncias que, posteriormente, vão se configurar como o sujeito e o objeto do conhecimento, numa teoria do conhecimento marcada pela representação em seus moldes clássicos. E a estratégia de ambos seria revelar, a partir de uma análise da percepção, a incongruência existente em supor essa percepção como um duplo de algo por natureza imperceptível; assim eles explicariam tal percepção sempre em termos de ação e, nesse sentido, de espiritualidade. No caso de Bergson, trata-se 
da ação do espírito, que se anuncia a partir já da indeterminação, introduzida pelos organismos vivos, sobre um universo de imagens que é comparado a uma grande consciência adormecida. No caso de Berkeley, trata-se da ação de Deus sobre os espíritos finitos. Ao resolver os problemas decorrentes do dualismo estrito, que colocava de um lado uma extensão sem forma e de outro uma consciência sem conteúdo, a teoria da percepção de Bergson explica como se dá efetivamente a ação da espiritualidade na extensão que configura a percepção. Isso implica explicitar todos os mecanismos de atuação da memória pelos quais aquele fundo de objetividade, que assegura a realidade de toda percepção, recebe os aportes da subjetividade (ao mesmo tempo em que se configuram concretamente, ou se individualizam, se subjetivizam). Berkeley, ao contrário, não se teria dado esse trabalho. Pois, como alcançar os meandros pelos quais a mente divina atinge, com os efeitos de sua atividade, cada uma das mentes individuais na percepção? Basta, aqui, mostrar o absurdo em afirmar que essa atividade reside no que é inerte.

Fiquemos com o acordo entre Berkeley e Bergson acima sugerido. No final das contas, ele não terá sido em vão se conseguirmos estabelecer um ponto comum entre ambas as filosofias: a caracterização desse aspecto negativo da intuição original inerente, segundo Bergson, a qualquer filosofia, intuição que impediu tanto Berkeley quanto Bergson de aceitar a irrealidade do mundo que nos cerca, resultado aparentemente incontornável dos dualismos de tipo cartesiano. Irrealidade que os levava a dizer Impossível toda vez que com ela depararam. ${ }^{13}$ Se assim for, se conseguirmos defender que Berkeley

13 "Parece-me que a intuição se comporta frequentemente, na especulação, como o demônio de Sócrates na vida prática; é ao menos sob essa forma que começa, e sob essa forma também que ela continua a se manifestar de maneira mais nítida: ela pró́be. Diante de ideias aceitas habitualmente, diante de teses que pareceriam evidentes, de afirmações que até então haviam passado por científicas, ela sopra na orelha do filósofo: Impossivel. (...) Força singular esse poder intuitivo de negação! Como não atraiu mais a atenção dos historiadores da filosofia? Não é visível que o primeiro movimento do filósofo, quando seu pensamento ainda está mal assentado e ele não tem nada de definitivo 
e Bergson partem dessa mesma intuição negativa e que ela desenha, desde o início, um universo distinto daquele do qual partem as teorias da representação, conseguiremos defender também que Berkeley tem em mente parâmetros que não se adequam a essas teorias. Nesse sentido, ele não amputa seus pressupostos nem se perde em um idealismo fantasioso, mas transforma os pressupostos dos quais havia partido. Teremos, então, dado um primeiro passo para caracterizar essas formas de desenvolvimento do pensamento que propõem uma alternativa ao quadro estruturado pela epistemologia moderna.

\section{Referências bibliográficas}

1. Bergson, H. Matière et memoire. Paris: PUF, 1999.

2.___. La pensée et le mouvant, Essais et Conferences. Paris: PUF, 1950.

3. Berkeley, G. Philosophical Commentaries (PC), A Tretise Concerning the Principles of Human Knowledge (PHK), Three Dialogues Between Hylas and Philonous (DHP). As três obras são citadas a partir da edição de A. A. Luce e T. E. Jessop, The Works of George Berkeley Bishop of Cloyne. Londres: T. Nelson, 1979, 2a ed., vol. I-III.

4. Fleming, N. "The tree in the quad". American Philosophical Quarterly, jan. 1985.

5. Prado Jr. B. Presença e campo transcendental — consciência e negatividade na filosofia de Bergson. São Paulo: Edusp, 1989.

em sua doutrina, é rejeitar certas coisas definitivamente? Mais tarde ele poderá variar em suas afirmações; jamais variará no que nega" (Bergson 2, p. 120). 
